\section{ANN AND GIS-ASSISTED METHODOLOGY FOR WIND RESOURCE ASSESSMENT (WRA) IN SARAWAK}

\author{
S. M. Lawana*, W. A. W. Z. Abidin' , A. M. Lawanc, M. Mustapha a, \\ S. L. Bichic
}

aDepartment of Electrical Engineering, Kano University of Science and Technology, Wudil Kano Nigeria bDepartment of Electrical and Electronic Engineering, Universiti Malaysia Sarawak (UNIMAS), Malaysia

cDepartment of Mathematical Science, Bayero University, Kano, Nigeria
Article history

Received

15 April 2015

Received in revised form

29 September 2015

Accepted

12 November 2015

*Corresponding author 13010004@siswa.unimas.my

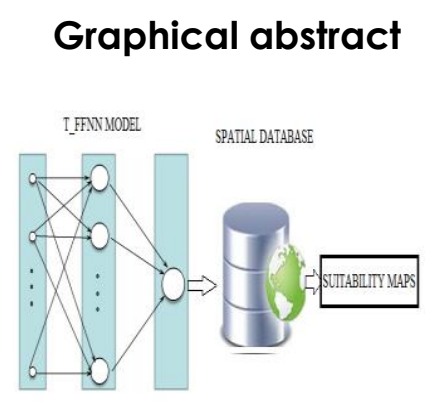

\begin{abstract}
Wind energy is a reliable, clean source and has emerged as one of the dependable, and the best performing developing renewable energy around the world. It has insignificant environmental impacts, compared to other energy sources. In Sarawak, Malaysia, wind resource varies depending on the location. An inadequate number of wind stations are the major obstacles that slow down the growing of green energy in the region. Site selection is a crucial issue for potential investors and policy makers. This paper examines the spatial distribution and the amount of potential wind power and energy densities for wind energy production and suitable locations in Sarawak. A geographical Information System (GIS) assisted methodology, which includes wind speed, power and energy densities using the existing wind station and based on the newly developed prediction model called topographical neural network (TNN) were used. Kriging interpolation was employed for a simple interpolation of data between locations. The results show that the northeast, northwest and coastal regions have better prospects of wind energy. The studied GIS methodology can be applied for identification of the most suitable locations for wind energy harvesting. The developed maps can further be used in micro-siting and economic evaluation analysis.
\end{abstract}

Keywords: GIS, wind energy, power density, kriging interpolation, Sarawak

(C) 2015 Penerbit UTM Press. All rights reserved

\subsection{INTRODUCTION}

Energy and environment are the most important concern in today's world. Fossil energy source (coal, gas and petroleum) pollutes the lower layer of the atmosphere, and boost the incidences of global warming directly or indirectly. Renewable energy solutions are naturally abundant, and a major competitor of conventional resources of energy. Among the renewable energy sources, wind power is thought to be the rapidly developed in terms of cumulative and yearly installed capacity [1,2].

Several research works are being done to examine the potential of wind power around the world [3-21]. In Malaysia, some studies have been performed using distribution models, spatial analysis and analytical assessment of wind power potential [22-29]. To be specific, two studies are identified in the case of Sarawak. Development of the wind map of Sabah and Sarawak using linear strength correlation method [30]. Research study on wind and 